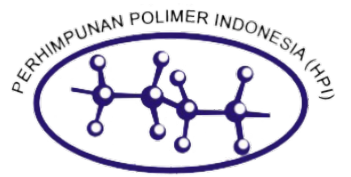

\title{
Life Cycle Assessment (LCA) Kantong Belanja Berbahan Plastik Daur Ulang, Goodie Bag dan Bioplastik
}

\begin{abstract}
A. Z. Abidin ${ }^{a}$, M. Nathania ${ }^{\text {a }}$, D. A. Trirahayu ${ }^{a}$
Menjaga kelestarian lingkungan alam merupakan suatu kewajiban bagi seluruh manusia. Karena alam sekitar merupakan tempat kita hidup dan mencari penghidupan baik berupa makanan, minuman dan semua kebutuhan kita untuk dapat bertahan hidup. Jika alam rusak maka manusia pula yang akan mendapat akibatnya. Seperti penebangan hutan yang tanpa aturan menyebabkan banjir sehingga lahan pertanian rusak dan petani pun merugi. Pengertian lama dari ramah lingkungan adalah suatu kegiatan yang bersifat biodegradable. Namun, saat ini telah ditemukan teknologi baru untuk mengolah sampah yang bersifat biodegradable serta non-biodegradable. Oleh sebab itu, definisi baru ramah lingkungan adalah sesuatu kegiatan yang sejalan dengan prinsip sustainability kehidupan dan tidak berdampak buruk terhadap lingkungan. Life Cycle Assessment (LCA) adalah proses untuk mengevaluasi dampak potensial suatu produk atau proses atau service terhadap lingkungan selama daur hidupnya. Life Cycle Assassment (LCA) dilakukan untuk 3 jenis kantong belanja yang sering digunakan di Indonesia yaitu: 1) Plastik daur ulang (recycle bag) berbahan HDPE, 2) Goodie Bag dan 3) Bioplastik. Berdasarkan lima tahap yang digunakan dalam analisis Life Cycle Assesment (LCA) yaitu bahan baku, proses pengolahan material menjadi produk, distribusi dan penyimpanan produk, penggunaan produk, serta pembuangan/daur ulang produk terpakai, maka kategori dampak lingkungan yang dibandingkan adalah bahan baku, proses produksi, distribusi dan penyimpanan produk, penggunaan produk dan daur ulang/pembuangan. Berdasarkan hasil penilaian Life Cycle Assessment (LCA), jenis kantong belanja diurutkan dari yang paling ramah lingkungan adalah plastik daur ulang, goodie bag dan bioplastik.
\end{abstract}

Protecting the natural environment is an obligation for all human beings. Because the natural environment is where we live and make a living either in the form of food, drink, and all our needs to be able to survive. If nature is damaged, then humans will also suffer the consequences. Such as illegal logging, which causes floods so that agricultural land is destroyed and farmers lose. The old understanding of environmentally friendly is an activity that is biodegradable. However, at this time, new technologies have been found to process waste that is biodegradable and non-biodegradable. Therefore, the new definition of environmentally friendly is something that is in line with the principle of sustainability of life and does not have a negative impact on the environment. Life cycle assessment (LCA) is a process to evaluate the potential impact of a product or process or service on the environment during its life cycle. Life Cycle Assessment (LCA) is carried out for 3 types of shopping bags that are often used in Indonesia, namely: 1) Recycled plastic made from HDPE, 2) Goodie Bag, and 3) Bioplastic. Based on the five stages used in the Life Cycle Assessment (LCA) analysis, namely raw materials, processing of materials into products, distribution, and storage of products, use of products, and disposal/recycling of used products, the categories of environmental impacts compared are raw materials, processes production, distribution and storage of products, product use, and recycling/disposal. Based on the results of the Life Cycle Assessment (LCA), the types of shopping bags sorted from the most environmentally friendly are recycled plastics, goodie bags, and bioplastics.

Kata kunci: Bioplastik, goodie bag, life cycle assessment, plastik daur ulang.

\section{Pendahuluan}

Menjaga kelestarian lingkungan alam merupakan suatu kewajiban bagi seluruh manusia. Karena alam sekitar merupakan tempat kita hidup dan mencari penghidupan baik berupa makanan, minuman dan semua kebutuhan kita untuk dapat bertahan hidup. Jika alam rusak maka manusia pula yang akan mendapat akibatnya. Seperti

\footnotetext{
a. Department of Chemical Engineering, Faculty of Industrial Technology, Institut Teknologi Bandung, Jl. Ganesa 10 Bandung, Indonesia 40132

† Corresponding author: zainal@che.itb.ac.id or mitraiqro@yahoo.com.
}

penebangan hutan yang tanpa aturan menyebabkan banjir sehingga lahan pertanian rusak dan petani pun merugi.

Pengertian lama dari ramah lingkungan adalah suatu kegiatan yang bersifat biodegradable. Namun, saat ini telah ditemukan teknologi baru untuk mengolah sampah yang bersifat biodegradable serta non-biodegradable. Oleh sebab itu, definisi baru ramah lingkungan adalah sesuatu kegiatan yang sejalan dengan prinsip sustainability kehidupan dan tidak berdampak buruk terhadap lingkungan.

Life Cycle Assessment (LCA) adalah proses untuk mengevaluasi dampak potensial suatu produk atau proses atau service terhadap lingkungan selama daur hidupnya. Konsep Life Cycle Assessment (LCA) terdiri dari lima tahap utama ${ }^{1}$ disajikan pada Gambar 1. 
Kelima tahap tersebut terdiri dari bahan baku, proses pengolahan material menjadi produk, distribusi dan penyimpanan produk, penggunaan produk, serta pembuangan/daur ulang produk terpakai.

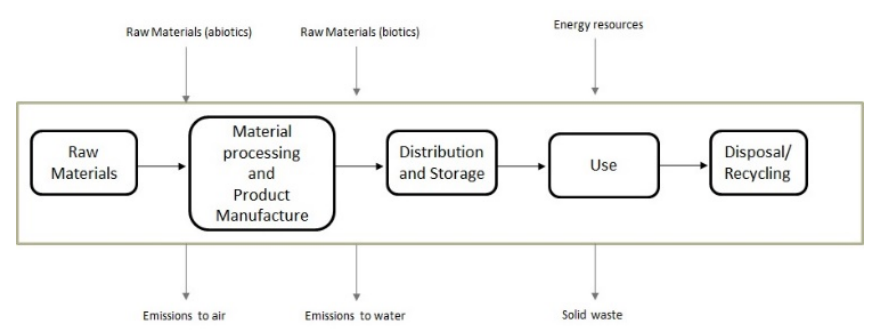

Gambar 1. Konsep Life Cycle Assassment. ${ }^{1}$

Life Cycle Assassment (LCA) digunakan untuk mempertimbangkan dampak lingkungan dari berbagai jenis kantong belanja mulai dari "bahan baku sampai ke pembuangan" dan bukan pada satu titik dalam konsep perhitungan Life Cycle Assassment (LCA). Berfokus pada satu titik dalam Life Cycle Assassment (LCA) atau kategori dampak tunggal dapat menghasilkan hasil yang hanya mengubah beban lingkungan dari satu area ke bidang lainnya. Pendekatan Life Cycle Assassment (LCA) membantu mengambil keputusan untuk mempertimbangkan dampak tindakan yang lebih luas.

Life Cycle Assassment (LCA) dilakukan untuk 3 jenis kantong belanja yang sering digunakan di Indonesia yaitu: 1) Plastik daur ulang (recycle bag) berbahan HDPE, 2) Goodie bag dan 3) Bioplastik. Studi ini menggunakan data studi literatur dan data real dari Perusahan Daur Ulang sampah plastik di Indonesia.

Berdasarkan lima tahap yang digunakan dalam analisis Life Cycle Assesment (LCA) yaitu bahan baku, proses pengolahan material menjadi produk, distribusi dan penyimpanan produk, penggunaan produk, serta pembuangan/daur ulang produk terpakai, maka kategori dampak lingkungan yang dibandingkan adalah bahan baku, proses produksi, distribusi dan penyimpanan produk, penggunaan produk dan daur ulang/pembuangan.

\section{Deskripsi Proses dan Siklus Hidup Kantong Be- lanja}

\section{Plastik Daur Ulang}

Metode daur ulang merupakan salah satu strategi pengolahan sampah plastik. Plastik daur ulang sebagian besar dapat dimanfaatkan kembali sebagai produk semula dengan kualitas yang lebih rendah. Pada tahun 1980an, di Inggris dan Italia plastik daur ulang telah digunakan untuk membuat tiang telepon sebagai pengganti tiangtiang kayu atau besi. Di Swedia, plastik daur ulang dimanfaatkan sebagai bata plastik untuk pembuatan bangunan bertingkat karena memiliki sifat ringan serta lebih kuat dibandingkan bata yang umum dipakai. ${ }^{9}$ Di Indonesia umumnya, plastik daur ulang digunakan kembali sebagai kantong belanja. Pemanfaatan sampah plastik dapat menjaga kelestarian lingkungan, meningkatkan nilai ekonomi benda yang bersangkutan, serta menguntungkan masyarakat tertentu yang mengelolanya. Diagram proses pembuatan plastik daur ulang ditampilkan pada Gambar 2.

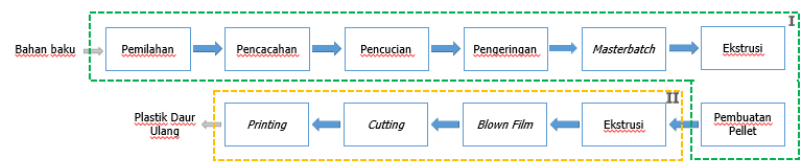

Gambar 2. Diagram proses pembuatan plastik daur ulang.

\section{Goodie Bag (Tas Kain)}

Tas kain merupakan salah satu jenis kantong belanja yang dapat digunakan kembali. Bahan baku yang umum digunakan untuk membuat tas kain adalah kain spunbond polipropilen. Polipropilen merupakan homopolimer yang digunakan secara luas dalam produksi kain bukan tenunan. Polipropilen memiliki beberapa keunggulan seperti ketahanan kimia yang baik, adsorpsi air yang hampir nol, harga yang terjangkau, serta mudah diperoleh. ${ }^{2}$ Tas kain polipropilen dapat bertahan selama 1-2 tahun. Berikut ini merupakan penjelasan detail proses pembuatan tas kain polipropilen non-woven. Diagram proses pembuatan tas kain ditampilkan pada Gambar 3.

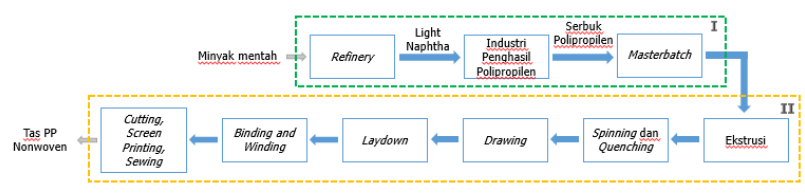

Gambar 3. Diagram proses pembuatan goodie bag (tas kain).

\section{Bioplastik}

Bioplastik dihasilkan dari hasil pengolahan sumber daya alam yang dapat diperbaharui, contohnya minyak nabati, pati, jagung, kentang, selulosa, gula dan lain-lain. Berdasarkan data Kementrian Pertanian tahun 2016, Indonesia merupakan negara penghasil ubi kayu terbesar ketiga di dunia dengan pangsa produksi sebesar $9,26 \%$ dan rata-rata produksi sebesar 23,90 juta ton. Indonesia memiliki potensi yang tinggi untuk mengolah pati singkong menjadi bioplastik. Menurut Janssen (2006), polimer pati memiliki beberapa keunggulan serta kekurangan. Polimer pati memiliki rantai yang fleksibel, ikatan yang kuat dan dapat didegradasi oleh mikroba. Namun, polimer tersebut bersifat rapuh, sensitif terhadap air, serta dapat terretrogradasi. Definisi retrogradasi adalah proses kristalisasi kembali dan pembentukan matrik pati yang telah mengalami gelatinisasi akibat pengaruh suhu. ${ }^{3}$ Produk bioplastik yang dihasilkan sebaiknya memenuhi beberapa persyaratan yaitu biodegradable, termoplastik $\left(\mathrm{Tm} \sim 90{ }^{\circ} \mathrm{C}\right)$, transparan, adanya pengontrolan retrogradasi, serta harga jual yang bekompetisi dengan jenis plastik lain. ${ }^{4}$ Diagram proses pembuatan bioplastik ditampilkan pada Gambar 4 .

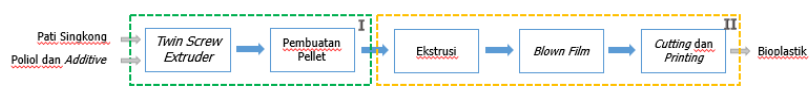

Gambar 4. Diagram proses pembuatan bioplastik. 


\section{Kalkulasi Life Cycle Assessment (LCA)}

\section{Bahan Baku}

Bahan baku berbagai jenis kantong belanja berbeda-beda. Bahan baku berbagai jenis kantong belanja ditampilkan dalam Tabel 1 .

Tabel 1. Bahan baku berbagai jenis kantong belanja

\begin{tabular}{|l|l|l|l|}
\hline Jenis Plastik & $\begin{array}{c}\text { Goodie Bag } \\
\text { (Tas Kain) }\end{array}$ & Bioplastik & $\begin{array}{c}\text { Plastik } \\
\text { Daur Ulang }\end{array}$ \\
\hline Bahan Baku & Minyak Bumi & Singkong & Sampah Plastik \\
\hline
\end{tabular}

Goodie bag (tas kain) juga berasal dari bahan baku minyak bumi yang diolah menjadi serbuk polipropilen dan mengalami proses spunbonding menjadi tas kain non-woven. Bioplastik berasal dari bahan baku singkong yang dimulai dari proses penanaman. Plastik daur ulang berasal dari bahan baku sampah plastik yang mengalami proses pengolahan kembali menjadi plastik yang dapat digunakan ulang. Perbedaan bahan baku berbagai jenis kantong belanja mempengaruhi dampak lingkungan kantong belanja tersebut.

\section{Proses Produksi}

\section{Kebutuhan Energi}

Kebutuhan energi utama dalam proses pembuatan plastik terdiri dari energi listrik dan bahan bakar. Bahan bakar yang dibutuhkan untuk transportasi bahan baku menuju pabrik tidak dimasukkan ke dalam perhitungan karena setiap negara memiliki kebiasaan serta kebijakan yang berbeda dalam hal transportasi sehingga tidak dapat dibandingkan. Basis perhitungan kebutuhan energi disajikan dalam satuan kWh kg-1 produk. Pada Tabel 2 disajikan kebutuhan energi utama dari berbagai sumber.

Tabel 2. Kebutuhan energi utama dalam proses pembuatan plastik

\begin{tabular}{|c|c|c|c|c|c|}
\hline No & Parameter & $\begin{array}{l}\text { Goodie Bag } \\
\text { (Tas Kain) }\end{array}$ & Bioplastik & $\begin{array}{l}\text { Plastik Daur } \\
\text { Ulang }\end{array}$ & Catatan \\
\hline \multirow[t]{2}{*}{1} & Primary Energy (MJ) & $\begin{array}{c}11,15 \\
(65,6 \mathrm{~g})\end{array}$ & $\begin{array}{c}0,12 \\
(12,5 \mathrm{~g})\end{array}$ & $\begin{array}{c}0,225 \\
(6 \mathrm{~g})\end{array}$ & \multirow{2}{*}{$\begin{array}{l}\text { Energi yang dibutuhkan dalam proses pembuatan } \\
\text { satu buah kantong plastik serta energi yang terkan- } \\
\text { dung dalam plastic. }{ }^{5}\end{array}$} \\
\hline & $\begin{array}{l}\text { Primary Energy } \\
\left(\mathrm{kWh} \mathrm{kg}^{-1}\right)\end{array}$ & 47,1945 & 2,6667 & 10,4167 & \\
\hline 2 & Energy Surplus (MJ) & 6,646 & 9,964 & 19,067 & $\begin{array}{l}\text { Energi tambahan yang dibutuhkan untuk menye- } \\
\text { diakan cadangan mineral dan bahan bakar akibat } \\
\text { pengurangan cadangan bahan bakar. }{ }^{1}\end{array}$ \\
\hline \multirow[t]{2}{*}{3} & Primary Energy (TJ) & - & 3959,4 & - & \multirow{2}{*}{$\begin{array}{l}\text { Energi listrik dan bahan bakar yang dibutuhkan un- } \\
\text { tuk memproduksi } 100.000 \text { ton resin plastik dari ba- } \\
\text { han baku berupa minyak (HDPE) dan pati singkong } \\
\text { (bioplastik). }{ }^{6}\end{array}$} \\
\hline & $\begin{array}{l}\text { Primary Energy } \\
\left(\mathrm{kWh} \mathrm{kg}^{-1}\right)\end{array}$ & - & 10,9983 & - & \\
\hline \multirow[t]{2}{*}{4} & Primary Energy (MJ) & 21,7 & - & - & \multirow{2}{*}{$\begin{array}{l}\text { Energi yang dibutuhkan dalam proses pembuatan } 1 \\
\text { kg polimer HDPE. }{ }^{7}\end{array}$} \\
\hline & $\begin{array}{l}\text { Primary Energy } \\
\left(\mathrm{kWh} \mathrm{kg}^{-1}\right)\end{array}$ & 6,0278 & - & - & \\
\hline \multirow[t]{2}{*}{5} & Primary Energy $\left(\mathrm{MJ} \mathrm{g}^{-1}\right)$ & 0,0027 & 0,0027 & 0,0038 & \multirow{2}{*}{$\begin{array}{l}\text { Energi listrik serta bahan bakar yang dibutuhkan } \\
\text { dalam proses pembuatan dari pelet plastik, kecuali } \\
\text { untuk goodie bag itu dari molten filament. }{ }^{8}\end{array}$} \\
\hline & $\begin{array}{l}\text { Primary Energy } \\
\left(\mathrm{kWh} \mathrm{kg}^{-1}\right)\end{array}$ & 0,7583 & 0,7583 & 1,0444 & \\
\hline
\end{tabular}

Berdasarkan hasil pembahasan, data pada Tabel 2 nomor 3 hingga 5 dapat digunakan untuk menghitung kebutuhan energi dari bahan baku hingga produk akhir. Perhitungan kebutuhan energi dibagi menjadi dua bagian utama. Bagian pertama yaitu proses pe- ngolahan dari bahan baku menjadi serbuk atau pellet, kemudian bagian kedua yaitu proses pengolahan dari serbuk atau pellet menjad kantong belanja. Pembagian kebutuhan energi untuk bagian I dan bagian II secara detail telah disajikan pada Gambar 2, 3 dan 4. Hasil perhitungan disajikan pada Tabel 3 dan Gambar 5.

Tabel 3. Hasil perhitungan kebutuhan energi dalam produksi berbagai jenis kantong belanja

\begin{tabular}{|c|c|c|c|c|}
\hline Parameter Jenis Plastik & $\begin{array}{l}\text { Goodie Bag } \\
\text { (Tas Kain) }\end{array}$ & Bioplastik & $\begin{array}{c}\text { Plastik } \\
\text { Daur Ulang }\end{array}$ & $\begin{array}{l}\text { *Data dari Asosiasi Pengusaha Daur Ulang Plastik Indone- } \\
\text { sia (APDUPI) }\end{array}$ \\
\hline $\begin{array}{l}\text { Kebutuhan Energi }\left(\mathrm{kWh} \mathrm{kg}^{-1}\right) \\
\text { dari bahan baku menjadi } \\
\text { pelet (bagian I) }\end{array}$ & $5,4014^{6-7}$ & $10,9983^{6}$ & - & \\
\hline $\begin{array}{l}\text { Kebutuhan Energi (kWh kg-1) } \\
\text { dari pelet menjadi kantong } \\
\text { belanja (bagian II) }\end{array}$ & $0,7583^{8}$ & $1,0444^{8}$ & - & \\
\hline $\begin{array}{l}\text { Kebutuhan Energi Total } \\
\left(\mathrm{kWh} \mathrm{kg-1}^{1}\right)\end{array}$ & 6,1597 & 12,0428 & $1,0955^{*}$ & \\
\hline
\end{tabular}




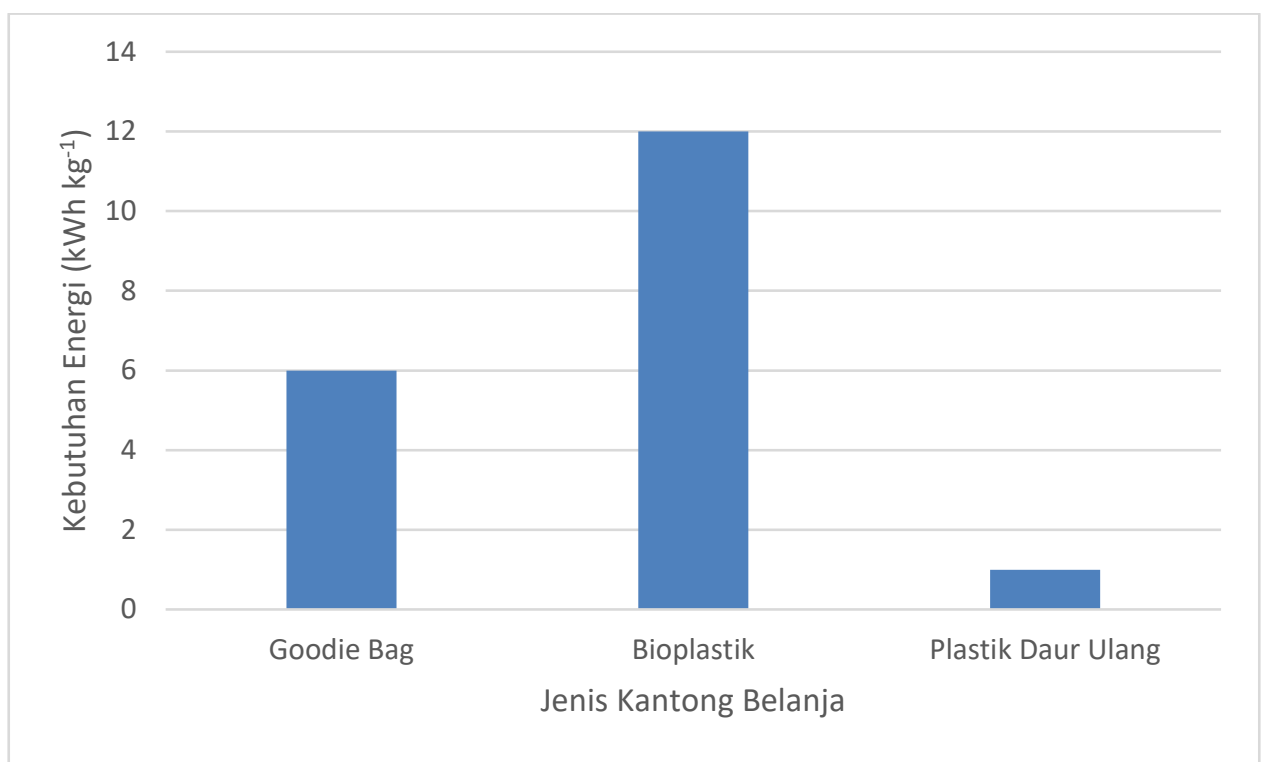

Gambar 5. Kebutuhan energi dalam produksi berbagai jenis kantong belanja.

Hasil perhitungan menunjukkan bahwa kebutuhan energi dari yang terkecil ke terbesar secara berurutan adalah plastik daur ulang, goodie bag dan bioplastik.

\section{Global Warming}

Produksi plastik dengan bahan bakar berbasis fosil menghasilkan emisi karbondioksida $\left(\mathrm{CO}_{2}\right)$ yang tinggi. Sumber emisi $\mathrm{CO}_{2}$ tertinggi merupakan proses steam cracking yang berkontribusi sekitar 1,52,5ton $\mathrm{CO}_{2}$ /ton etilen dan 0,7-1,3ton $\mathrm{CO}_{2} /$ ton $\mathrm{HV}^{10}$ Dampak yang dihasilkan akibat pemanasan global, khususnya perubahan iklim, semakin nyata. Dampak ini umumnya disebabkan oleh penggunaan bahan bakar fosil serta produk turunan fosil. Saat ini, berbagai upaya untuk menggantikan bahan bakar fosil dengan bahan bakar terbarukan dilakukan. Subbab ini membahas potensi pemanasan global dari ketiga jenis kantong belanja.

Tabel 4. Potensi pemanasan global dari produksi berbagai jenis kantong belanja

\begin{tabular}{|c|c|c|c|}
\hline $\begin{array}{l}\text { Jenis Plastik } \\
\text { Parameter }\end{array}$ & $\begin{array}{l}\text { Goodie Bag } \\
\text { (Tas Kain) }\end{array}$ & Bioplastik & $\begin{array}{c}\text { Plastik } \\
\text { Daur Ulang }\end{array}$ \\
\hline $\begin{array}{l}\text { Potensi Pemanasan } \\
\text { Global (kg } \mathrm{CO}_{2} / \mathrm{kg} \\
\text { produk) }\end{array}$ & 4,7971 & 10,4343 & 0,7994 \\
\hline
\end{tabular}

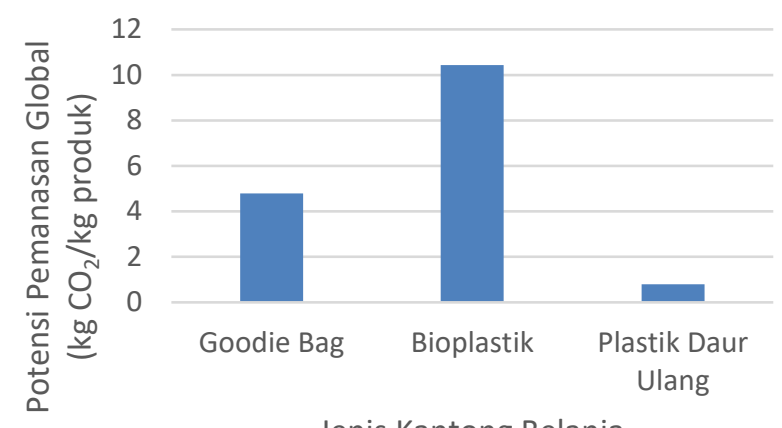

Jenis Kantong Belanja

Gambar 6. Potensi pemanasan global dari produksi berbagai jenis kantong belanja.
Potensi pemanasan global ( $\mathrm{kg} \mathrm{\textrm {CO } _ { 2 }}$ ekivalen) disajikan pada Tabel 4 dan Gambar 6. Berdasarkan data Menteri ESDM No. 3783/21/600.5/2008, rata-rata emisi karbon 2015 sebesar 0,867. Namun emisi karbon tersebut belum termasuk emisi solar.Hasil perhitungan menunjukkan bahwa emisi karbon dioksida terbesar ke terkecil secara berurutan dihasilkan dari proses produksi bioplastik, goodie bag (tas kain) dan plastik daur ulang.

\section{Kebutuhan Lahan}

Data kebutuhan lahan diperoleh dari Sustainable Packaging Alliance Limited, 2009. Data tersebut diolah ke dalam satuan per kilogram produk plastik. Hasil pengolahan data ditampilkan pada Tabel 5.

Tabel 5. Kebutuhan lahan berbagai jenis kantong belanja

\begin{tabular}{|l|c|c|c|}
\hline \multicolumn{1}{|c|}{ Jenis Plastik } & $\begin{array}{c}\text { Goodie Bag } \\
\text { (Tas Kain) }\end{array}$ & Bioplastik & $\begin{array}{c}\text { Plastik } \\
\text { Daur Ulang }\end{array}$ \\
\hline $\begin{array}{l}\text { Kebutuhan } \\
\text { Lahan }\left(\mathbf{m}^{\mathbf{2}} \mathbf{~ k g}^{-1}\right)\end{array}$ & $0,027778^{1}$ & $0,82835^{1}$ & $0,02228^{*}$ \\
\hline
\end{tabular}

*Data dari Asosiasi Pengusaha Daur Ulang Plastik Indonesia (APDUPI)

Kebutuhan lahan untuk produksi plastik oxo-biodegradable disamakan dengan kebutuhan lahan untuk produksi plastik HDPE $100 \%$ virgin karena dalam produksi plastik oxo-biodegradable hanya dibutuhkan tambahan alat pencampur pellet plastik dengan aditif oxium dibandingkan produksi plastik HDPE $100 \%$ virgin.

Kebutuhan lahan untuk produksi goodie bag (tas kain) lebih besar dibandingkan kebutuhan lahan untuk produksi plastik HDPE $100 \%$ virgin karena dalam proses pembuatan goodie bag (tas kain) membutuhkan alat-alat proses spunbonding. Kebutuhan lahan untuk produksi plastik daur ulang paling sedikit karena proses dimulai dari bahan baku berupa sampah plastik, sedangkan jenis plastik lain dimulai dari bahan baku berupa pati singkong, dan minyak mentah. Dapat disimpulkan bahwa kebutuhan lahan dari yang terkecil ke terbesar secara berurutan adalah plastik daur ulang, plastik HDPE 
$100 \%$ virgin, plastik oxo-biodegradable, goodie bag (tas kain) dan bioplastik.

\section{Kebutuhan Air}

Data kebutuhan air diperoleh dari Sustainable Packaging Alliance Limited, 2009. Data tersebut diolah ke dalam satuan per kilogram produk plastik agar dapat dibandingkan. Hasil pengolahan data ditampilkan pada Tabel 6 dan Gambar 7.

Tabel 6. Kebutuhan air dalam proses produksi berbagai jenis kantong belanja

\begin{tabular}{|l|c|c|c|}
\hline Jenis Plastik & $\begin{array}{c}\text { Goodie Bag } \\
\text { (Tas Kain) }\end{array}$ & Bioplastik & $\begin{array}{c}\text { Plastik } \\
\text { Daur Ulang }\end{array}$ \\
\hline $\begin{array}{l}\text { Kebutuhan Air } \\
\text { (kL kg }\end{array}$ & $0,027778^{1}$ & $0,82835^{1}$ & $1,12 \times 10^{-3 *}$ \\
\hline
\end{tabular}

* Asosiasi Pengusaha Daur Ulang Plastik Indonesia (APDUPI)

Kebutuhan air total yang dibutuhkan untuk memproduksi bioplastik jauh lebih besar bila dibandingkan dengan jenis kantong belanja lainnya karena memerlukan air mulai dari penanaman singkong sampai menjadi bioplastik. Kebutuhan air total untuk produksi goodie bag (tas kain) lebih besar dari plastik daur ulang. Kebutuhan air untuk produksi plastik daur ulang paling sedikit karena air hanya dibutuhkan untuk proses pencucian dan pembuatan pellet. Sedangkan proses pembuatan jenis kantong belanja lainnya dimulai dari bahan baku berupa pati singkong dan minyak mentah. Dapat disimpulkan bahwa kebutuhan air dari yang terkecil ke terbesar secara berurutan adalah plastik daur ulang, goodie bag (tas kain) dan bioplastik.

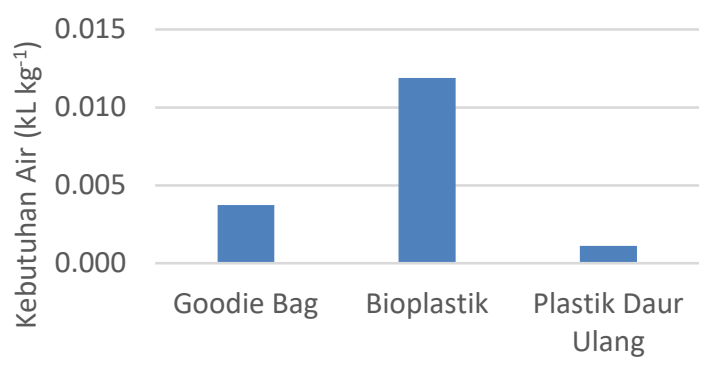

Jenis Kantong Belanja

Gambar 7. Kebutuhan air dalam produksi berbagai jenis kantong belanja.

\section{Harga}

Perbandingan harga berbagai macam jenis kantong belanja diperoleh dari survey lapangan di pasaran. Hasil survey lapangan di pasaran ditampilkan dalam Tabel 7. Harga goodie bag (tas kain) paling mahal dibandingkan jenis kantong belanja lainnya karena goodie bag (tas kain) dapat dipakai beberapa kali dibandingkan dengan jenis kantong belanja lainnya. Harga bioplastik lebih mahal dibandingkan plastik daur ulang karena harga bahan baku bioplastik (singkong) lebih mahal dibandingkan minyak bumi. Harga plastik daur ulang paling murah dibandingkan jenis kantong belanja lainnya karena bahan baku plastik daur ulang adalah sampah plastik yang dicampur dengan pellet plastik virgin dan diolah kembali menjadi plastik guna ulang.
Tabel 7. Harga berbagai jenis kantong belanja

\begin{tabular}{|l|c|c|c|}
\hline \multicolumn{1}{|c|}{ Jenis Plastik } & $\begin{array}{c}\text { Goodie Bag } \\
\text { (Tas Kain) }\end{array}$ & Bioplastik & $\begin{array}{c}\text { Plastik } \\
\text { Daur Ulang }\end{array}$ \\
\hline Harga (Rp/kg) & $85.000,00$ & $35.000,00$ & $20.300,00^{[a, b]}$ \\
\hline $\begin{array}{l}\text { Harga } \\
\text { (Rp/lembar) }\end{array}$ & 9800,00 & 600,00 & 150,00 \\
\hline
\end{tabular}

[a] PT. Multiplas Kreatif Mandiri

[b] Asosiasi Perusahaan Daur Ulang Plastik Indonesia (APDUPI)

\section{Distribusi dan Penyimpanan (Distribution and Storage)}

Massa dan volume produk adalah faktor yang mempengaruhi transportasi dan penyimpanan produk. Massa dan volume berbagai jenis kantong belanja ditampilkan dalam Tabel 8 .

Tabel 8. Massa dan volume berbagai jenis kantong belanja

\begin{tabular}{|l|c|c|c|}
\hline Jenis Plastik & $\begin{array}{c}\text { Goodie Bag } \\
\text { (Tas Kain) }\end{array}$ & Bioplastik & $\begin{array}{c}\text { Plastik } \\
\text { Daur Ulang }\end{array}$ \\
\hline Massa (g) & $115,83^{8}$ & $16,49^{8}$ & $7,7^{1}$ \\
\hline Volume (cm ${ }^{3}$ ) & $19.750^{8}$ & $19.100^{8}$ & $21.600^{1}$ \\
\hline
\end{tabular}

Massa dan volume goodie bag (tas kain) lebih besar dibandingkan jenis kantong belanja lainnya karena goodie bag (tas kain) memiliki bahan yang tebal sehingga dapat digunakan beberapa kali. Massa dan volume volume goodie bag (tas kain) yang lebih besar dibandingkan jenis kantong belanja lainnya menyebabkan transportasi dan penyimpanan yang dibutuhkan goodie bag (tas kain) lebih besar dibandingkan jenis kantong belanja lainnya. Massa dan volume bioplastik lebih besar dibandingkan plastik daur ulang karena bahan baku pembuatan bioplastik yaitu singkong juga memiliki massa yang besar sehingga transportasi dan penyimpanan yang dibutuhkan bioplastik juga lebih besar dibandingkan plastik daur ulang. Plastik daur ulang memiliki massa dan volume yang paling kecil karena plastik daur ulang adalah pengolahan kembali sampah plastik HDPE sehingga transportasi dan penyimpanan yang dibutuhkan plastik daur ulang juga lebih kecil dibandingkan jenis kantong belanja lainnya.

\section{Penggunaan (Use)}

Analisis terhadap use (penggunaan) berbagai jenis kantong belanja oleh masyarakat Indonesia pada umumnya ditampilkan dalam Tabel 9.

Tabel 9. Penggunaan berbagai jenis kantong belanja

\begin{tabular}{|l|c|c|c|}
\hline Jenis Plastik & $\begin{array}{c}\text { Goodie Bag } \\
\text { (Tas Kain) }\end{array}$ & Bioplastik & $\begin{array}{c}\text { Plastik } \\
\text { Daur Ulang }\end{array}$ \\
\hline $\begin{array}{l}\text { Penggunaan } \\
\text { (kali) }\end{array}$ & $14^{8}$ & 1 & 2 \\
\hline
\end{tabular}

Goodie bag (tas kain) dapat digunakan berkali-kali (14 kali) sampai goodie bag (tas kain) mengalami kerusakan sehingga tidak dapat digunakan lagi. Bioplastik juga hanya dapat digunakan satu kali karena memiliki sifat yang cukup rapuh apabila terkena air sehingga tidak dapat digunakan sebagai kantong sampah. 


\section{Daur Ulang/Pembuangan (Recycling/Disposal)}

Recycling/Disposal adalah pilihan metode pengolahan yang sebaiknya dilakukan terhadap sampah kantong belanja. Selain kedua metode tersebut, terdapat pilihan lain yaitu reuse dan insinerasi. Analisis terhadap metode pengolahan sampah kantong belanja ditampilkan dalam Tabel 10.

Tabel 10. Metode pengolahan sampah kantong belanja

\begin{tabular}{|l|c|c|c|}
\hline Jenis Plastik & $\begin{array}{c}\text { Goodie Bag } \\
\text { (Tas Kain) }\end{array}$ & Bioplastik & $\begin{array}{c}\text { Plastik } \\
\text { Daur Ulang }\end{array}$ \\
\hline Recycling & & & \\
\hline Reuse & Ansineration/ & A A A & \\
\hline Pirolisis & A A A A & A A A \\
\hline Disposal & A A & A A A & A A \\
\hline
\end{tabular}

$\begin{array}{ll}\text { AAA A } & \text { : Prioritas pertama } \\ \text { A A } & \text { : Prioritas kedua } \\ \text { A } & \text { : Prioritas ketiga } \\ & \text { : Tindakan terakhir }\end{array}$

Goodie bag (tas kain) memang bersifat sebagai kantong belanja multiple use (pemakaian berkali-kali). Pengelolaan sampah goodie bag (tas kain) adalah dengan dibakar. Tindakan pembuangan sampah goodie bag (tas kain) ke TPA/TPS (landfill) tetap harus menjadi pilihan terakhir, karena penimbunan sampah di TPA/TPS (landfill) bukanlah solusi dalam pengelolaan sampah agar tidak menjadi beban bagi masyarakat sekitar dan Pemerintah. Selain itu sampah goodie bag juga dapat didaur ulang karena terbuat dari polipropilen dan dapat diolah menjadi produk lain.

Sampah bioplastik didesain untuk dibuang ke TPA/TPS (landfill) karena bersifat biodegradable. Apabila sampah plastik sudah tidak bisa digunakan dapat ditangani dengan insinerasi/pirolisis sampah plastik menjadi bahan bakar. Metode terakhir yang dapat digunakan yaitu reuse (penggunaan kembali). Sampah bioplastik memiliki ketahanan yang kurang kuat dan tidak tahan terhadap air.

Sampah plastik daur ulang dapat di recycle (daur ulang) menjadi plastik daur ulang. Selain itu plastik daur ulang dapat digunakan kembali hingga rusak. Apabila sampah daur ulang sudah tidak memenuhi standar untuk di-recycle atau digunakan kembali, dapat ditangani dengan insinerasi/pirolisis sampah plastik menjadi bahan bakar. Tindakan pembuangan sampah plastik ke TPA/TPS (landfill) harus menjadi pilihan terakhir dalam pengelolaan sampah plastik jika tidak ada alat konversi sampah plastik menjadi BBM, karena penimbunan sampah di TPA/TPS (landfill) bukanlah solusi dalam pengelolaan sampah tetapi beban bagi masyarakat sekitar dan pemerintah.

\section{Penilaian Life Cycle Assessment (LCA)}

Pada Tabel 11, disajikan rangkuman hasil perhitungan dari subbab Kebutuhan Energi hingga Harga.

Tabel 11. Rangkuman hasil perhitungan LCA

\begin{tabular}{|c|c|c|c|c|}
\hline No & $\begin{array}{ll}\text { Parameter } & \text { Jenis Plastik } \\
\end{array}$ & $\begin{array}{l}\text { Goodie Bag } \\
\text { (Tas Kain) }\end{array}$ & Bioplastik & $\begin{array}{c}\text { Plastik } \\
\text { Daur Ulang }\end{array}$ \\
\hline 1 & Kebutuhan energi total $\left(\mathrm{kWh} \mathrm{kg}^{-1}\right)$ & 6,1597 & 12,0428 & 1,0955 \\
\hline 2 & $\begin{array}{l}\text { Potensi Pemanasan Global } \\
\text { ( } \mathrm{kg} \mathrm{CO} / \mathrm{kg} \text { produk) }\end{array}$ & 4,7971 & 10,4343 & 0,7994 \\
\hline 3 & Kebutuhan Lahan $\left(\mathrm{m}^{2} \mathrm{~kg}^{-1}\right)$ & 0,027778 & 0,82835 & 0,02228 \\
\hline 4 & Kebutuhan Air $\left(\mathrm{kL} \mathrm{kg}^{-1}\right)$ & 0,00372 & 0,0119 & 0,00112 \\
\hline 5 & Harga (Rp/kg) & 85.000 & 35.000 & 20.300 \\
\hline 6 & Harga (Rp/lembar) & 9.800 & 600 & 150 \\
\hline 7 & Penggunaan (kali) & 14 & 1 & 2 \\
\hline
\end{tabular}

Dari hasil perhitungan tersebut, dilakukan penilaian dengan menggunakan skala. Jenis plastik yang menunjukkan nilai parameter yang paling kecil diberikan skala 10, sedangkan jenis plastik yang menunjukkan parameter yang paling besar diberikan skala 5. Kemudian, dilakukan perhitungan sehingga diperoleh skor sebagai berikut. Skor penilaian parameter-parameter tersebut disajikan pada Tabel 12.

Tabel 12. Skala penilaian parameter berbagai jenis kantong plastik

\begin{tabular}{|c|l|c|c|c|}
\hline No Jenis Plastik & $\begin{array}{c}\text { Goodie Bag } \\
\text { (Tas Kain) }\end{array}$ & Bioplastik & $\begin{array}{c}\text { Plastik Daur } \\
\text { Ulang }\end{array}$ \\
\hline 1 & Karameter & 8 & 5 & 10 \\
\hline 2 & $\begin{array}{l}\text { Potensi Pemanasan Global } \\
\text { (kg CO } / \mathrm{kg} \text { produk) }^{-1} \text { ) }\end{array}$ & 8 & 5 & 10 \\
\hline 3 & Kebutuhan Lahan $\left(\mathrm{m}^{2} \mathrm{~kg}^{-1}\right)$ & 10 & 5 & 10 \\
\hline 4 & Kebutuhan Air $\left(\mathrm{kL} \mathrm{kg}^{-1}\right)$ & 9 & 5 & 10 \\
\hline 5 & Harga (Rp/kg) & 5 & 9 & 10 \\
\hline 6 & Harga (Rp/lembar) & 5 & 10 & 10 \\
\hline 7 & Pengolahan sampah & 9 & 5 & 10 \\
\hline \multicolumn{2}{r}{ Total skor } & 53 & 44 & 70 \\
\hline
\end{tabular}

Hasil penilaian dapat menunjukkan jenis plastik yang ramah lingkungan dan kurang ramah lingkungan dari berbagai parameter. Jenis plastik diurutkan dari yang paling ramah lingkungan (skor tinggi ke rendah) adalah plastik daur ulang, goodie bag, dan bioplastik. Dengan demikian, dapat disimpulkan dari hasil penilaian Life Cycle Assessment bahwa jenis plastik yang paling ramah lingkungan adalah plastik daur ulang. 


\section{Kesimpulan}

Kesimpulan dari hasil perhitungan di atas adalah sebagai berikut.

1. Kebutuhan energi dari yang terkecil ke terbesar secara berurutan adalah plastik daur ulang, goodie bag (tas kain) dan bioplastik.

2. Emisi karbondioksida dari yang terkecil ke terbesar secara berurutan dihasilkan dari proses produksi plastik daur ulang, goodie bag (tas kain) dan bioplastik.

3. Kebutuhan lahan dari yang terkecil ke terbesar secara berurutan adalah plastik daur ulang, goodie bag (tas kain) dan bioplastik.

4. Kebutuhan air dari yang terkecil ke terbesar secara berurutan adalah plastik daur ulang, goodie bag (tas kain) dan bioplastik.

5. Harga kantong belanja per lembar diurutkan dari yang terkecil ke terbesar adalah plastik daur ulang, bioplastik dan goodie bag.

Dengan demikian, berdasarkan hasil penilaian Life Cycle Assessment (LCA), jenis kantong belanja diurutkan dari yang paling ramah lingkungan adalah plastik daur ulang, goodie bag dan bioplastik.

\section{Referensi}

1 The Sustainable Packaging Alliance Limited. 2009. Environmental Impacts of Shopping Bags. Melbourne, Australia.

2 Y. Yuan, W. Jian, Z. Yanan, G. Mingqiao, Researches on Preparation and Properties of Polypropylene Nonwovens Containing Rare Earth Luminous Materials, Journal of Rare Earths, 2014, 32(12), 1196-2000.

3 E. Widyastuti. 2012. Modifikasi Pati. Slide Kuliah Teknologi Pangan Universitas Brawijaya.
4 L.P.B.M. Janssen. 2006. Thermoplastic Starch. University of Groningen: Netherlands.

5 S. Muthu dan L. Yi. 2014. Assesment of Environmental Impact by Grocery Shopping Bags. Springer Singapore Heidelberg New York Dordrecht London.

6 S. Chiarakom, C.K. Permpoonwiwat, P. Nanthachatchavankul. 2014. Financial and Economic Viability of Bioplastik Production in Thailand. WorldFish (ICLARM)-Economy and Environment Program for Southeast Asia (EEPSEA): Philipina.

7 Association of Plastic Manufacture Plastic Europe. 2008. Environemtal Product Declarations of the European Plastics Manufactures High Density Polyethylene (HDPE). Polyolefins Group, PlasticEurope: Belgia.

8 C. Edwards. 2011. Life cycle assessment of supermarket carrier bags: a review of the bags available in 2006. Environment Agency, Horizon House, Deanery Road, Bristol. Inggris.

9 R. Dilli. 2007. Comparison of existing life cycle analysis of shopping bag alternatives. Victoria: Australia.

10 D.J. Gielen, J. Podkanski, Technological potentials for $\mathrm{CO}_{2}$ emission reduction in the global iron and steel industry, Proceedings Ishii symposium on sustainable ironmaking, 2006, Cooperative Research Centre for Coal in Sustainable Development CCSD, Brisbane, Australia.

11 J. Greene. 2015. Life Cycle Assessment of Reusable and Singleuse Plastic Bags in California. California State University: Chico.

12 H. Kansal. 2016. Experimental Investigation of Properties of Polypropylene and Non-Woven Spunbond Fabric. Vimal Indusries: India.

13 A.F. Nugroho. 2012. Sintesis Bioplastik dari Pati Ubi Jalar Menggunakan Penguat Logam ZnO dan Penguat Alami Clay. Universitas Indonesia: Depok.

14 A. Saptorahardjo. 2016. ENVIPLAST: Starch Based Bioplastik Compound. Prosiding Seminar Nasional Kulit, Karet dan Plastik Ke-5. ISSN: 2477-3298. Yogyakarta, 26 Oktober 2016. 